\title{
A 3-year longitudinal study of skeletal effects and growth in children after kidney transplantation
}

Diana Swolin-Eide, Sverker Hansson and Per Magnusson

The self-archived postprint version of this journal article is available at Linköping University Institutional Repository (DiVA):

http://urn.kb.se/resolve?urn=urn:nbn:se:liu:diva-151195

N.B.: When citing this work, cite the original publication.

Swolin-Eide, D., Hansson, S., Magnusson, P., (2018), A 3-year longitudinal study of skeletal effects and growth in children after kidney transplantation, Pediatric Transplantation, 22(6), e13253.

https://doi.org/10.1111/petr.13253

Original publication available at:

https://doi.org/10.1111/petr.13253

Copyright: Wiley (12 months)

http://eu.wiley.com/WileyCDA/ 


\title{
A 3-year longitudinal study of skeletal effects and growth in children after kidney transplantation
}

\author{
Diana Swolin-Eide ${ }^{1}$, Sverker Hansson ${ }^{1}$, Per Magnusson ${ }^{2}$ \\ Department of Pediatrics, Institute for Clinical Sciences, The Queen Silvia Children's \\ Hospital, The Sahlgrenska Academy at Göteborg University, SE-416 85 Göteborg, Sweden \\ Department of Clinical Chemistry, and Department of Clinical and Experimental Medicine, \\ Linköping University, SE-581 85 Linköping, Sweden
}

1

2

E-mail addresses: diana.swolin-eide@vgregion.se, sverker.hansson@ pediat.gu.se, per.magnusson@regionostergotland.se

\begin{abstract}
Abbreviations: 1,25(OH)2D, 1,25-dihydroxyvitamin D; 25(OH)D, 25-hydroxyvitamin D; ALP, alkaline phosphatase; BMC, bone mineral content; BMD, bone mineral density; BMI, body mass index; CKD, chronic kidney disease; CKD-MBD, chronic kidney disease mineral and bone disorder; CTX, carboxy-terminal cross-linking telopeptide of type I collagen; DXA, dual-energy X-ray absorptiometry; DXL, dual-energy X-ray absorptiometry with laser; GFR, glomerular filtration rate; GH, growth hormone; GP, Greulich-Pyle; OPG, osteoprotegerin; PINP, type I procollagen intact amino-terminal propeptide; PTH, parathyroid hormone; RIA, radioimmunoassay; SD, standard deviation; SDS, standard deviation score; TBBMD, total body bone mineral density;TRACP5b, tartrate-resistant acid phosphatase isoform 5b; TW2, Tanner-Whitehouse 2 .
\end{abstract}

\section{Corresponding author:}

Per Magnusson, $\mathrm{PhD}$, Professor

Department of Clinical Chemistry

Department of Clinical and Experimental Medicine

Linköping University

SE-581 85 Linköping

Sweden

Tel: +46-10-103 3997

E-mail: per.magnusson@regionostergotland.se 
Authors: Swolin-Eide D, Hansson S, Magnusson P

Title: A 3-year longitudinal study of skeletal effects and growth in children after kidney transplantation

Journal: Pediatr Transplant

Abstract: This prospective study investigated growth and skeletal development for 3 years after kidney transplantation in pediatric patients, 3.4-15.0 years of age. Growth, bone mineral density (BMD), bone resorption markers (CTX and TRACP5b), bone formation markers (PINP, alkaline phosphatase and osteocalcin), parathyroid hormone and vitamin D were assessed at start, 3, 12 and 36 months after transplantation. Median glomerular filtration rate was 63 (range 37-96) $\mathrm{mL} / \mathrm{min} / 1.73 \mathrm{~m}^{2}$ after 3 years. The median height standard deviation score (SDS) increased from -1.7 to -1.1 , and median body mass index (BMI) SDS increased from -0.1 to 0.6 over 3 years, which shows that transplantation had a favorable outcome on growth. Fat mass increased after transplantation at all time points, whereas lean mass increased after 1 year and 3 years. Total bone mineral content (BMC) increased at all time points. No changes were observed for total BMD. Bone resorption markers decreased initially after 3 months, and remained stable throughout the study, whereas the bone formation markers decreased initially, but successively increased over the study period. In conclusion, this study demonstrates that height SDS and BMI SDS increased, along with the increased formation markers that reveal a positive bone acquisition after kidney transplantation, which was reflected by the significant increase in total body BMC.

KEYWORDS: pediatric kidney transplantation, bone markers, bone mineral density, dualenergy X-ray absorptiometry, growth, body composition 


\section{INTRODUCTION}

Childhood chronic kidney disease (CKD) is associated with disordered mineral metabolism with long-term consequences such as skeletal deformities, decreased bone accrual, fractures and growth retardation. ${ }^{1,2}$ In 2009, and recently updated 2017, the international Kidney Disease Improving Global Outcome (KDIGO) initiative summarized the multitude of known complications and pathophysiological processes related to mineral dysregulation in CKD by introducing the new concept of CKD - mineral and bone disorder (CKD-MBD). ${ }^{3}$ The disordered mineral homeostasis is characterized by abnormalities in calcium, phosphate, parathyroid hormone (PTH) and vitamin D metabolism, and current guidelines aim at treating these mineral abnormalities. However, it should be noted that the interpretation of bone mineral measurements is more complex in children than in adults since children are growing individuals. ${ }^{4,5}$ The term bone health is usually used in the pediatric bone field as a general term for longitudinal growth, mineral homeostasis and bone acquisition relating to the cortical and trabecular compartments. Pediatric prospective long-term studies about growth, bone mass and mineral metabolism in children with CKD have shown that these patients benefit from regular monitoring. ${ }^{6-8}$ Dual-energy X-ray absorptiometry (DXA) is regarded as the clinical method of choice for measuring bone mass in young individuals. An alternative method for pediatric use is the DXA with laser (DXL) Calscan technique, which measures trabecular bone in the calcaneus. Values of bone mineral density (BMD) in children, obtained by DXA and DXL, correlate well with each other. ${ }^{9}$

Kidney transplantation has emerged into an effective treatment option for end-stage renal disease. Long-term survival rates have dramatically improved over the last couple of decades with over $80 \%$ of pediatric patients surviving into adolescence and young adulthood. ${ }^{10}$ With reduced complications, improved graft outcome and patient survival rates, potential adverse events after long-term immunosuppressive medication have become 
increasingly important to address. Children undergoing solid organ transplantation have an elevated risk for fractures, which warrants attention to bone health in this group of pediatric patients. A population-based prospective study reported that the incidence of all fractures was 6-fold higher and the incidence for vertebral fractures was 160-fold higher in the study group in comparison with the control population. ${ }^{11}$ Although there is compelling knowledge about optimization of bone health in pediatric transplant recipients, ${ }^{12}$ previous studies have consequently emphasized continued efforts of clinical research for improving bone health of this population. ${ }^{13-15}$

Little is known about markers of bone turnover in pediatric patients with CKD after kidney transplantation. These markers are classified as either resorption or formation markers that provide a quantitative estimate of the current rate of bone remodeling. For the clinical interpretation, it is important to be aware of that children and adolescents can have 10-fold higher serum levels in comparison with adults. ${ }^{16}$ Bone markers reflect the three physiologic processes interacting in the bone environment, i.e., modeling, remodeling, and longitudinal growth, and can also be used to monitor the biological response to pharmacological treatment. ${ }^{17,18}$ For patients with CKD, it should be noted that the clinical usefulness is uncertain for carboxy-terminal cross-linking telopeptide of type I collagen (CTX) and osteocalcin since they are cleared by the kidneys. ${ }^{7}$ Hence, reduced renal clearance leads inevitably to increased serum levels of CTX and osteocalcin. Serum type I procollagen intact amino-terminal propeptide (PINP), alkaline phosphatase (ALP) and tartrate-resistant acid phosphatase isoform 5b (TRACP5b) may have added clinical utility in patients with CKD since their clearance from the circulation is independent of kidney function. ${ }^{19}$

This longitudinal study was designed to access the development of growth, BMD, bone mineral content (BMC) and biomarkers of bone and mineral metabolism in pediatric patients with CKD during a 3-year period after kidney transplantation. 


\section{PATIENTS AND METHODS}

\subsection{Patients}

Patients were recruited from the Queen Silvia Children's Hospital after informed consent from the children and their parents. The mean follow-up time was 1030 days. The local research ethics committee of Göteborg University, Sweden, approved this study (no. Ö37401). The study group, at baseline comprised 13 patients with CKD, 9 males and 4 females, median age 9.3 years (3.4-15.0 years) at inclusion. Glomerular filtration rate (GFR) was calculated according to the formula by Schwartz et al. ${ }^{20}$ Underlying nephropathy types were malformation $(n=8)$, Laurence-Moon-Biedl syndrome $(n=1)$, and acquired diseases $(n=4)$. Conservative treatment was given when indicated with sodium bicarbonate, calcium carbonate and alphacalcidol but no patients received aluminum containing phosphate binders before the transplantation. Antihypertensive treatment was given when indicated. Eleven patients received their first transplant and two patients their second transplant. Six patients received treatment with recombinant human growth hormone $(\mathrm{GH})$ before transplantation. Five patients had early rejections and received intravenous methyl prednisolone for 3-4 days. Our immunosuppression protocol included daily steroids for 3 months (Table 1), thereafter on alternate days for at least another 3 months, calcineurin inhibitors and mycophenolate mofetil.

\subsection{Assessment of bone mass and bone age}

BMD and BMC for total body were assessed by the Lunar DPX IQ (pencil beam), (GE Lunar Corp., Madison, WI, USA). DXA measures bone in 2 dimensions and this areal bone mineral density, and not true volumetric bone mineral density, is referred to BMD $\left(\mathrm{g} / \mathrm{cm}^{2}\right)$ in this study. The calculated Z-scores were age- and gender-specific. Lean body mass and fat mass were also measured. In the DXL Calscan technique, BMD is measured by using DXA in combination with laser measurements of the total heel thickness. This technology reduces the 
uncertainty related to the variable composition of soft tissue in adults. ${ }^{21}$ For calcaneal BMD, the DXL Calscan (Demetech AB, Täby, Sweden) has been used for diagnosis of osteoporosis in adults and is in conjunction with measurements by axial DXA technology. ${ }^{22,23}$ The original DXL Calscan for adults has been modified for use in pediatric patients and has been shown to measure BMD with high accuracy. ${ }^{24}$ The DXL Calscan pediatric version includes a function, which makes it possible to measure the calcaneal height. This height, together with the BMD value, provides an opportunity to calculate the volumetric bone mineral apparent density, which could be valuable when measuring bones of different sizes as, e.g., for growing individuals. ${ }^{24}$ The left foot of each child was measured. Regular hand X-ray was used to assess signs of rickets and to assess bone age by the Tanner-Whitehouse 2 (TW2) and Greulich-Pyle (GP) methods at the Department of Radiology, The Queen Silvia Children's Hospital, Göteborg, Sweden.

\subsection{Biochemical determinations}

A detailed description of the biochemical methods applied has been reported elsewhere. ${ }^{25}$ Serum intact PINP was determined by radioimmunoassay (RIA) (Orion Diagnostica, Oulunsalo, Finland). Serum total ALP was measured by a kinetic assay with $1.0 \mathrm{M}$ diethanolamine buffer (pH 9.8), $1.0 \mathrm{mM} \mathrm{MgCl}_{2}$ and $10 \mathrm{mM}$ p-nitrophenylphosphate. The relation between the ALP activity units kat and U are $1.0 \mu \mathrm{kat} / \mathrm{L}$ corresponds to $60 \mathrm{U} / \mathrm{L}$. Serum osteocalcin was determined by RIA, OSTKPR (CIS Bio International, Gif-sur-Yvette, Cedex, France). The serum osteoclast-derived TRACP5b was determined by a solid-phase immunofixed enzyme activity assay (SBA Sciences, Oulu, Finland). Type I collagen degradation was assessed by the serum CrossLaps ELISA (Immunodiagnostic Systems Ltd, Boldon, UK), which is reported to measure a cathepsin $\mathrm{K}$ degradation product of trivalently cross-linked type I collagen, i.e., CTX. Serum PTH was measured with an 
electrochemiluminescence immunoassay, ECLIA (Roche Diagnostics Scandinavia AB, Göteborg, Sweden). Osteoprotegerin (OPG) is an anti-resorptive cytokine and a key-regulator of osteoclastogenesis and activity. Serum OPG was measured by a sandwich enzyme-linked immunosorbent assay (Immundiagnostik AG, Bensheim, Germany). Pediatric age- and gender-specific reference intervals are reported elsewhere for PTH, OPG, total ALP, PINP, osteocalcin, CTX and TRACP5b. ${ }^{25}$ Serum 25-hydroxyvitamin D (25(OH)D) and 1,25dihydroxyvitamin D $\left(1,25(\mathrm{OH})_{2} \mathrm{D}\right)$ were determined by ${ }^{125}$ I RIAs (DiaSorin, Stillwater, MN, USA). Serum levels for total calcium, ionized calcium, magnesium and phosphate were assayed by routine clinical chemistry assays at the Department of Clinical Chemistry (SWEDAC accredited laboratory) at Sahlgrenska University Hospital, Göteborg, Sweden.

\subsection{Statistical analysis}

All calculations were performed with the SAS software release 9.3 (SAS Institute, Cary, NC, USA). Wilcoxon signed rank test was used to test for differences between study entry and the different time points. The level of significance was set to $\mathrm{p}<0.05$. Total body BMC was the primary efficacy variable and our primary efficacy analyze was the change in total body BMC from baseline to 3 years. The standard deviation (SD) for change in total body BMC from baseline to 3 years has been estimated to $272 \mathrm{~g}$. In order to find a clinical relevant change in total body BMC from baseline to 3 years of $250 \mathrm{~g}$ with a power of $80 \%$ with Wilcoxon signed rank test for paired observation, at significance level $0.05,13$ evaluable subjects are needed.

\section{RESULTS}

Clinical information before transplantation and clinical outcome are presented in Table 1. As a result of the kidney transplantation, GFR (expressed as $\mathrm{mL} / \mathrm{min} / 1.73 \mathrm{~m}^{2}$ ) increased to median (minimum-maximum) 68 (42-90), 65 (48-109) and 63 (37-96), at 3 months, 1 year 
and 3 years post-transplantation, respectively. No significant change in GFR was observed between 3 months and 1 year, or between 3 months and 3 years post-transplantation. Individual GFR values over the study period are shown in Table 1. Further statistical assessments of subgroups based on different CKD-stages were not justified due to the small study group.

\subsection{Growth and body composition}

Figure 1 shows auxological data for weight, height and BMI standard deviation score (SDS) for each patient over the study period. Median weight SDS was $-1.3,-0.5,-0.5$, and -0.4 at start, 3 months, 1 year and 3 years, respectively. The corresponding values for median height SDS was $-1.7,-1.7,-1.3$, and -1.1 ; and for median BMI SDS $-0.1,0.9,1.2$, and 0.6. In comparison with baseline, significant increases were found for weight SDS ( $\mathrm{p}=0.0002)$, height SDS ( $\mathrm{p}=0.0012$ ), and BMI SDS ( $\mathrm{p}=0.013$ ) after 3 years. According to the age- and gender-adjusted Swedish classification of overweight, ${ }^{26} 6$ and 4 patients were overweight after 1 year and 3 years, respectively, after kidney transplantation. The fat mass percentage increased after transplantation (from median $12.9 \%$ to $27.4 \%$ ), $\mathrm{p}<0.01$, and total lean mass was unchanged after 3 months, but increased after 1 year and 3 years (from median $23.1 \mathrm{~kg}$ $(84.3 \%)$ at baseline to $29.3 \mathrm{~kg}(70.4 \%)$ after 3 years $), \mathrm{p}<0.01$.

\subsection{Bone mass and bone age}

Bone mass data, i.e., BMC and BMD, are presented in Table 2 for total body and calcaneus measurements. Total BMC increased at all time points in comparison with the initial values at study start, $\mathrm{p}<0.001$ (Table 2; Figure 2). No change was observed for total BMD over the study period, which is reflected by the decrease in total body BMD (TBBMD) Z-score over 
the study period. None of the included patients had a TBBMD Z-score below -2.0 during the study period. Calcaneal BMC and BMD did not change at any time point.

At start, we observed a delayed median bone age by 0.9 years (TW2) and 0.8 years (GP) in comparison with the chronological age. Bone age was still delayed after 3 years posttransplantation, i.e., 1.5 years (TW2) and 0.9 years (GP). Two patients sustained clavicule fractures during the study period, but no other fractures were reported.

\subsection{Biochemical markers of bone and mineral metabolism}

Median PTH was $254 \mathrm{ng} / \mathrm{L}$ prior transplantation, but decreased rapidly to $81 \mathrm{ng} / \mathrm{L}$ after 3 months $(\mathrm{p}<0.01)$ and remained stable throughout the first year after transplantation. An additional decrease was observed between 3 months and 3 years, median $69 \mathrm{ng} / \mathrm{L}(\mathrm{p}<0.05)$. A similar pattern of decrease was found for serum phosphate after 3 months and 3 years $(\mathrm{p}<0.05)$, as well as for magnesium after 3 months and 3 years $(\mathrm{p}<0.01)$. No effect was found for serum 25(OH)D after 3 months and 1 year, but an increase was found after 3 years $(\mathrm{p}<0.05)$. The levels of $1,25(\mathrm{OH})_{2} \mathrm{D}$ increased after the first year and 3 years $(\mathrm{p}<0.002)$ in comparison with baseline. Serum total calcium and ionized calcium remained unchanged throughout the post-transplantation period. Median serum OPG decreased from $4.1 \mathrm{pmol} / \mathrm{L}$ at baseline to $2.8 \mathrm{pmol} / \mathrm{L} 3$ months post-transplantation, $\mathrm{p}<0.01$, but returned to baseline levels after 1 year and 3 years.

Individual data (percentage change from baseline) for the bone resorption markers, CTX and TRACP5b, and bone formation markers intact PINP, total ALP and osteocalcin are shown in Figure 3. Serum CTX decreased significantly after 3 months, 1 year and 3 years in comparison with baseline values, $\mathrm{p}<0.01$, which is in line with the increased GFR levels at each time-point after kidney transplantation (Table 1). Serum TRACP5b decreased initially after 3 months $(\mathrm{p}<0.05)$, and remained stable throughout the study period. PINP decreased 
after 3 months ( $\mathrm{p}<0.05)$, but returned to baseline levels 1 year and 3 years posttransplantation. Total ALP was unchanged until 3 months, but increased between 3 months

and 1 year post-transplantation $(\mathrm{p}<0.01)$. Serum osteocalcin decreased significantly during the first 3 months $(p<0.0005)$, but increased thereafter during the study period $(p<0.002)$ (Figure 3). Further statistical assessments of subgroups based on gender, age, growth patterns, CKDstages or estimated cumulative steroid dosages were not justified due to the small study group.

\section{DISCUSSION}

This is one of few prospective studies in children with CKD regarding growth, bone markers and bone acquisition after kidney transplantation. Risk factors for persisting CKD-MBD with impaired bone health after transplantation are immunosuppressive therapy (calcineurin inhibitors and steroids), persistent hyperparathyroidism, deranged vitamin D metabolism and allograft dysfunction. The present study demonstrates that median height SDS, BMI SDS and total BMC increased during the study period, which shows that kidney transplantation had a favorable impact on growth outcomes. Bone resorption markers decreased initially and remained stable throughout the study period, whereas the bone formation markers increased successively.

Growth failure is a frequent complication of CKD and GH treatment is, therefore, commonly used to enhance growth in children with CKD. ${ }^{12}$ Kidney transplantation is, however, the best treatment for growth-deficient children with CKD, which results in a sustained increase in height and restoration of body proportions in most patients. ${ }^{27} \mathrm{We}$ observed a similar increase in height in the current study, that is, median height SDS increased from -1.7 to -1.1 after 3 years, and median BMI SDS increased from -0.1 to 0.6 after 3 years, which shows that transplantation had a favorable impact on growth outcomes. Zivicnjak et al. ${ }^{28}$ reported, from a 7-year cohort study, a specific age-dependent growth 
pattern in pediatric CKD patients. The most severe growth failure was observed during early childhood, followed by an accelerated growth during prepuberty, slowing-down of growth at puberty, and thereafter a late catch-up growth until early adulthood. It has been suggested that growth failure in CKD is caused by a relative GH insensitivity and functional insulin-like growth factor-I deficiency. ${ }^{29}$ Growth restriction is very common in children with CKD, and the assessment of skeletal maturity (bone age) is an important prerequisite to evaluating the individual growth delay and growth potential. ${ }^{30}$ Median radiological bone age was still delayed after 3 years in the current study.

Bone and fat mass are linked, thus changes in body composition after kidney transplantation affect growth and skeletal development in children. The fat mass percentage increased after transplantation in the current study, at all time points, whereas lean mass increased after 1 year and 3 years. Treatment with glucocorticoids, after kidney transplantation, cause an initial increase in fat mass which later on is reduced with a subsequent increase in lean mass as patients recovers and probably increase their mobility and degree of physical activity. The increase in lean mass is favorable for bone acquisition, as muscle mass affect bone mass positively. ${ }^{31}$ Our findings coincide with a Hungarian pediatric study where the prevalence of overweight/obese patients was low at transplantation and rose subsequently. ${ }^{32}$ In another Scandinavian cohort, one-third of the pediatric patients were overweight/obese after kidney transplantation, ${ }^{33}$ which was not found in the current study as most patients had a median BMI SDS of 0.6.

A 2015 meta-analysis indicates that BMD is low in patients with CKD stage 3-5 with fractures, which suggests that BMD measurements may be clinically useful in assessing fracture risk in CKD. ${ }^{34}$ DXA has been recommended to follow-up kidney transplant recipients. ${ }^{14,35,36}$ Recent studies measuring BMD by DXA have demonstrated that low BMD is common in pediatric kidney transplant recipients. ${ }^{13,37,38} \mathrm{An}$ increase in total BMC, at all 
time points, was found which corroborate with the significant increase in height SDS and thereby positive net gain in mineral acquisition. None of the included patients had a TBBMD Z-score below -2.0 during the study period, which indicates an appropriate management of their bone and mineral homeostasis. Interpretation of BMD changes must, however, be done with caution, since changes in body composition may affect the measurements per se, because imaging techniques like DXA have some difficulties to differentiate between newly acquired adipose tissue and newly formed bone tissue in growing children. ${ }^{39}$ A 2014 prospective study with CKD children, 1 year after kidney transplantation, suggested that spine and total body DXA provides some insight into trabecular and cortical compartments following transplantation..$^{40}$

The interpretation of biochemical markers of bone and mineral metabolism is complex in growing children and adolescents due to the multifaceted mechanism of longitudinal growth. ${ }^{41}$ Another aspect to take into account, regarding interpretation of bone formation markers, is the three major events during osteogenesis, i.e., proliferation with collagen synthesis, extracellular matrix maturation and mineralization. In vitro studies have shown a sequential expression of genes during osteoblast differentiation, that is, messenger RNA of type I collagen is expressed first, followed by ALP, and finally osteocalcin. ${ }^{42}$ In vivo studies have shown a corresponding time course for the three different stages following the circulating levels of bone formation markers PINP, ALP and osteocalcin during anabolic growth hormone treatment. ${ }^{41}$ Although that kidney transplantation favors the acquisition of bone mineral, as shown by the increase in total body BMC, it cannot be regarded as a definite anabolic treatment in the same fashion as growth hormone. The lack of uniformity for ALP, shown in Figure 3 during the course of the current study, may reveal different effects for different patients during the extracellular matrix maturation phase of osteogenesis. This is the first prospective study investigating pediatric kidney transplant patients comprising data from 
markers of bone turnover. The initial decrease, 3 months after kidney transplantation, for the bone formation markers (except for ALP) was followed by a significant increase between 3 months and 1 year after transplantation for all formation markers. Both PINP and osteocalcin increased between 3 months and 3 years after transplantation. The bone resorption markers (i.e., CTX and TRACP5b) decreased initially and remained stable throughout the study period. The observed alterations in bone markers corroborate with the significant increase in total body BMC. However, it should be noted that the clinical usefulness of CTX is uncertain in patients with CKD since CTX is cleared by the kidneys; hence reduced renal clearance inevitably leads to increased levels of CTX. Circulating levels of bone markers represents an overall assessment of the modelling and remodeling processes in the entire skeleton, which can differ between different skeletal sites and different bone compartments such as trabecular and cortical bone. ${ }^{43}$ Fratzl-Zelman et al. ${ }^{44}$ demonstrated recently a broad heterogeneity in bone matrix mineralization in pediatric solid-organ recipients by bone histomorphometry, which further explains some of the observed alterations bone material properties that impact skeletal fragility.

The current study has a number of strengths, including the prospective design, broad approach with the combination of growth evaluation, body composition, bone mass measurements and markers of bone and mineral metabolism. The low number of patients is a limitation of the study that warrant consideration when interpreting the data. On a positive note, the current study comprise only data from kidney transplant recipients, thus it is not a blend of solid-organ transplant patients which often is reported in the literature. We lacked matching controls in this study but there is currently no consensus on the optimal approach for control-matching BMD and BMC for factors such as body composition, pubertal stage and skeletal maturity. 
Bone health in children and adolescents has emerged as a significant area of clinical interest, and expanding area of research, since many chronic diseases affect the skeleton with long-term consequences. Worldwide, more and more children benefit from kidney transplantation and prospective studies are therefore warranted. This longitudinal prospective study demonstrates that height SDS and BMI SDS increased, along with the increased markers of bone formation that reveal positive bone acquisition after kidney transplantation, which was reflected by the significant increase in total body BMC.

\section{ACKNOWLEDGEMENTS}

We thank all the patients and parents for participating in this study. We are grateful to Christina Linnér, Anne Dohsé, and Cecilia Halling Linder for excellent technical assistance. We thank the staff at the Pediatric Uronephrological Center, The Queen Silvia Children's Hospital, Göteborg. We acknowledge the expert statistical advice of Anders Pehrsson. This study was supported by the Swedish Government under the agreement between the Government and the County Councils concerning economic support of medical research and education (the ALF agreement), the Memorial Foundation Professor Lars-Erik Gelin and ALF Grants Region Östergötland, Sweden.

\section{AUTHORS' CONTRIBUTIONS}

Diana Swolin-Eide, Sverker Hansson and Per Magnusson: Participated in concept/design, data analysis/interpretation, drafting article, data collection, participated in critical revision of article and final approval of article. 


\section{REFERENCES}

1. Denburg MR, Kumar J, Jemielita T, et al. Fracture burden and risk factors in childhood CKD: results from the CKiD cohort study. J Am Soc Nephrol. 2016;27:543-550.

2. Hanudel MR, Salusky IB. Treatment of pediatric chronic kidney disease-mineral and bone disorder. Curr Osteoporos Rep. 2017;15:198-206.

3. KDIGO 2017 Clinical practice guideline update for the diagnosis, evaluation, prevention, and treatment of chronic kidney disease-mineral and bone disorder (CKDMBD). Kidney Int Suppl. 2017;7:1-59.

4. Kuizon BD, Salusky IB. Growth retardation in children with chronic renal failure. $J$ Bone Miner Res. 1999;14:1680-1690.

5. Leonard MB. Assessment of bone mass following renal transplantation in children. Pediatr Nephrol. 2005;20:360-367.

6. Wetzsteon RJ, Kalkwarf HJ, Shults J, et al. Volumetric bone mineral density and bone structure in childhood chronic kidney disease. J Bone Miner Res. 2011;26:2235-2244.

7. Swolin-Eide D, Hansson S, Magnusson P. Skeletal effects and growth in children with chronic kidney disease: a 5-year prospective study. J Bone Miner Metab. 2013;31:322328.

8. Holmberg C, Jalanko H. Long-term effects of paediatric kidney transplantation. Nat Rev Nephrol. 2016;12:301-311.

9. Söderpalm A-C, Kullenberg R, Swolin-Eide D. The relationship between dual energy X-ray absorptiometry (DXA) and DXA with laser (DXL) measurements in children. $J$ Clin Densitom. 2008;11:555-560.

10. Larosa C, Baluarte HJ, Meyers KE. Outcomes in pediatric solid-organ transplantation. Pediatr Transplant. 2011;15:128-141. 
11. Helenius I, Remes V, Salminen S, et al. Incidence and predictors of fractures in children after solid organ transplantation: a 5-year prospective, population-based study. J Bone Miner Res. 2006;21:380-387.

12. Sgambat K, Moudgil A. Optimization of bone health in children before and after renal transplantation: current perspectives and future directions. Front Pediatr. 2014;2:1-11.

13. Sgambat K, Tuchman S, Ryan L, Wood R, Moudgil A. Low bone mineral density and nutritional vitamin D deficiency in pediatric renal transplant recipients: assessment of risk factors and response to oral vitamin D therapy. Pediatric Transplant. 2011;15:790797.

14. Bianchi ML, Leonard MB, Bechtold S, et al. Bone health in children and adolescents with chronic diseases that may affect the skeleton: the 2013 ISCD Pediatric Official Positions. J Clin Densitom. 2014;17:281-294.

15. Büyükkaragöz B, Bakkaloglu SA, Kandur Y, et al. The evaluation of bone metabolism in children with renal transplantation. Pediatric Transplant. 2015;19:351-357.

16. Magnusson P, Häger A, Larsson L. Serum osteocalcin and bone and liver alkaline phosphatase isoforms in healthy children and adolescents. Pediatr Res. 1995;38:955961.

17. Greenblatt MB, Tsai JN, Wein MN. Bone turnover markers in the diagnosis and monitoring of metabolic bone disease. Clin Chem. 2017;63:464-474.

18. Eastell R, Szulc P. Use of bone turnover markers in postmenopausal osteoporosis. Lancet Diabetes Endocrinol. 2017;5:908-923.

19. Sardiwal S, Magnusson P, Goldsmith DJA, Lamb EJ. Bone alkaline phosphatase in CKD-mineral bone disorder. Am J Kidney Dis. 2013;62:810-822. 
20. Schwartz GJ, Haycock GB, Edelmann Jr CM, Spitzer A. A simple estimate of glomerular filtration rate in children derived from body length and plasma creatinine. Pediatrics. 1976;58:259-269.

21. Hakulinen MA, Saarakkala S, Töyräs J, Kröger H, Jurvelin JS. Dual energy x-ray laser measurement of calcaneal bone mineral density. Phys Med Biol. 2003;48:1741-1752.

22. Kullenberg R, Falch JA. Prevalence of osteoporosis using bone mineral measurements at the calcaneus by dual X-ray and laser (DXL). Osteoporos Int. 2003;14:823-827.

23. Martini G, Valenti R, Gennari L, Salvadori S, Galli B, Nuti R. Dual X-ray and laser absorptiometry of the calcaneus: comparison with quantitative ultrasound and dualenergy X-ray absorptiometry. J Clin Densitom. 2004;7:349-354.

24. Söderpalm A-C, Kullenberg R, Albertsson-Wikland K, Swolin-Eide D. Pediatric reference data for bone mineral density in the calcaneus for healthy children 2 , 4 , and 7 years of age by dual-energy X-ray absorptiometry and laser. J Clin Densitom. 2005;8:305-313.

25. Swolin-Eide D, Hansson S, Larsson L, Magnusson P. The novel bone alkaline phosphatase B1x isoform in children with kidney disease. Pediatr Nephrol. 2006;21:1723-1729.

26. Karlberg J, Luo ZC, Albertsson-Wikland K. Body mass index reference values (mean and SD) for Swedish children. Acta Paediatr. 2001;90:1427-1434.

27. Franke D, Thomas L, Steffens R, et al. Patterns of growth after kidney transplantation among children with ESRD. Clin J Am Soc Nephrol. 2015;10:127-134.

28. Živičnjak M, Franke D, Filler G, et al. Growth impairment shows an age-dependent pattern in boys with chronic kidney disease. Pediatr Nephrol. 2007;22:420-429.

29. Tönshoff B, Kiepe D, Ciarmatori S. Growth hormone/insulin-like growth factor system in children with chronic renal failure. Pediatr Nephrol. 2005;20:279-289. 
30. Haffner D, Schaefer F, Nissel R, Wühl E, Tönshoff B, Mehls O. Effect of growth hormone treatment on the adult height of children with chronic renal failure. German study group for growth hormone treatment in chronic renal failure. $N$ Engl J Med. 2000;343:923-930.

31. Frost HM. Obesity, and bone strength and "mass": a tutorial based on insights from a new paradigm. Bone. 1997;21:211-214.

32. Degi AA, Kis E, Kerti A, Cseprekal O, Szabo AJ, Reusz GS. Prevalence of obesity and metabolic changes after kidney transplantation: Hungarian pediatric cohort study. Transplant Proc. 2014;46:2160-2163.

33. Tangeraas T, Midtvedt K, Fredriksen PM, Cvancarova M, Morkrid L, Bjerre A. Cardiorespiratory fitness is a marker of cardiovascular health in renal transplanted children. Pediatr Nephrol. 2010;25:2343-2350.

34. Bucur RC, Panjwani DD, Turner L, Rader T, West SL, Jamal SA. Low bone mineral density and fractures in stages 3-5 CKD: an updated systematic review and metaanalysis. Osteoporos Int. 2015;26:449-458.

35. Kulak CA, Borba VZ, Kulak J, Jr., Custodio MR. Osteoporosis after transplantation. Curr Osteoporos Rep. 2012;10:48-55.

36. Gupta AK, Huang M, Prasad GV. Determinants of bone mineral density in stable kidney transplant recipients. J Nephrol. 2012;25:373-383.

37. Ellis EN, Floyd-Gimon DM, Berry PL, Wells TG, Seibert J, Belsha C. Risk factors for bone mineral density loss in pediatric renal transplant patients. Pediatric Transplant. 2000;4:146-150.

38. Daniels MW, Wilson DM, Paguntalan HG, Hoffman AR, Bachrach LK. Bone mineral density in pediatric transplant recipients. Transplantation. 2003;76:673-678. 
39. Hannan WJ, Tothill P, Cowen SJ, Wrate RM. Whole body bone mineral content in healthy children and adolescents. Arch Dis Child. 1998;78:396-397.

40. Tsampalieros A, Griffin L, Terpstra AM, et al. Changes in DXA and quantitative CT measures of musculoskeletal outcomes following pediatric renal transplantation. Am J Transplant. 2014;14:124-132.

41. Andersson B, Swolin-Eide D, Magnusson P, Albertsson-Wikland K. Short-term changes in bone formation markers following growth hormone $(\mathrm{GH})$ treatment in short prepubertal children with a broad range of GH secretion. Clin Endocrinol. 2015;82:9199.

42. Stein GS, Lian JB, Stein JL, Van Wijnen AJ, Montecino M. Transcriptional control of osteoblast growth and differentiation. Physiol Rev. 1996;76:593-629.

43. Magnusson P, Larsson L, Magnusson M, Davie MWJ, Sharp CA. Isoforms of bone alkaline phosphatase: characterization and origin in human trabecular and cortical bone. J Bone Miner Res. 1999;14:1926-1933.

44. Fratzl-Zelman N, Valta H, Pereira RC, et al. Abnormally high and heterogeneous bone matrix mineralization after childhood solid organ transplantation: a complex pathology of low bone turnover and local defects in mineralization. $J$ Bone Miner Res. 2017;32:1116-1125. 
TABLE 1 Clinical information before and after transplantation

\begin{tabular}{|c|c|c|c|c|c|c|c|c|c|c|c|c|}
\hline \multirow{2}{*}{$\begin{array}{l}\text { Patient } \\
\text { no. }\end{array}$} & \multirow{2}{*}{ Gender } & \multirow{2}{*}{$\begin{array}{c}\text { Age } \\
\text { (years) }\end{array}$} & \multirow{2}{*}{ Diagnosis } & \multicolumn{4}{|c|}{ GFR (mL/min/1.73 m²) } & \multirow{2}{*}{$\begin{array}{c}\text { Estimated } \\
\text { cumulative steroid } \\
\text { dose }(\mathrm{mg} / \mathrm{kg}) \\
3 \text { months; } 1 \text { year; } \\
3 \text { years }\end{array}$} & \multirow[b]{2}{*}{ Clinical outcome } & \multirow{2}{*}{\multicolumn{2}{|c|}{$\begin{array}{c}25(\mathrm{OH}) \mathrm{D} \\
(\mu \mathrm{g} / \mathrm{L}) \\
\text { Before } \\
\text { Tx } \\
\end{array}$}} & \multirow{2}{*}{$\begin{array}{c}\text { GH therapy } \\
\text { Before } \\
\text { Tx } \\
\end{array}$} \\
\hline & & & & $\begin{array}{c}\text { Before } \\
\text { Tx }\end{array}$ & $\begin{array}{c}3 \\
\text { months }\end{array}$ & $\begin{array}{c}1 \\
\text { year }\end{array}$ & $\begin{array}{c}3 \\
\text { years }\end{array}$ & & & & & \\
\hline 1 & Female & 8 & Dysplasia & $\begin{array}{c}\text { ND } \\
\text { (dialysis) }\end{array}$ & 65 & 58 & 56 & $26 ; 49 ; 49$ & Uneventful & $122 ; 53$ & 19 & $\begin{array}{c}\text { Yes } \\
\text { (3 years) }\end{array}$ \\
\hline 2 & Male & 8 & Dysplasia & 17 & 71 & 109 & 87 & $26 ; 78 ; 191$ & Uneventful & $162 ; 29$ & 35 & No \\
\hline 3 & Male & 10 & Dysplasia & $\begin{array}{c}\text { ND } \\
\text { (dialysis) }\end{array}$ & 55 & 70 & 54 & $22 ; 71 ; 128$ & $\begin{array}{c}\text { Second transplant } \\
\text { Uneventful }\end{array}$ & $948 ; 69$ & 31 & No \\
\hline 4 & Male & 5 & PUV & $\begin{array}{c}\text { ND } \\
\text { (dialysis) }\end{array}$ & 75 & 59 & 53 & $128 ; 202 ; 292$ & Early rejection & $646 ; 86$ & 20 & No \\
\hline 5 & Male & 8 & PUV & 20 & 65 & 65 & 63 & $21 ; 71 ; 113$ & $\begin{array}{l}\text { Second transplant } \\
\text { Uneventful }\end{array}$ & $342 ; 74$ & 10 & $\begin{array}{c}\text { Yes } \\
\text { (1.5 years) }\end{array}$ \\
\hline 6 & Male & 9 & PUV & 13 & 83 & 87 & 73 & $21 ; 59 ; 129$ & Uneventful & $102 ; 69$ & 47 & $\begin{array}{c}\text { Yes } \\
\text { (3.5 years) }\end{array}$ \\
\hline 7 & Male & 13 & PUV & $\begin{array}{c}\text { ND } \\
\text { (dialysis) }\end{array}$ & 42 & 57 & 37 & $52 ; 77 ; 158$ & $\begin{array}{c}\text { Early and late } \\
\text { rejection }\end{array}$ & $128 ; 16$ & 61 & No \\
\hline 8 & Male & 15 & PUV & 14 & 73 & 65 & 68 & $66 ; 66 ; 66$ & Early rejection & $1440 ; 55$ & 17 & $\begin{array}{c}\text { Yes } \\
(6 \text { years })\end{array}$ \\
\hline 9 & Male & 4 & $\begin{array}{c}\text { Laurence- } \\
\text { Moon-Biedl }\end{array}$ & $\begin{array}{c}\text { ND } \\
\text { (dialysis) }\end{array}$ & 87 & 73 & 66 & $45 ; 106 ; 173$ & Uneventful & $294 ; 112$ & ND & No \\
\hline 10 & Female & 6 & $\begin{array}{c}\text { Interstitial } \\
\text { nephritis }\end{array}$ & $\begin{array}{c}\text { ND } \\
\text { (dialysis) }\end{array}$ & 58 & 54 & 51 & $24 ; 61 ; 116$ & Uneventful & $82 ; 69$ & 5 & No \\
\hline 11 & Female & 11 & DDD & $\begin{array}{c}\text { ND } \\
\text { (dialysis) }\end{array}$ & 90 & 85 & 96 & $16 ; 33 ; 56$ & Uneventful & $660 ; 106$ & 29 & No \\
\hline 12 & Male & 14 & FSGS & $\begin{array}{c}\text { ND } \\
\text { (dialysis) }\end{array}$ & 68 & 74 & 63 & $80 ; 103 ; 134$ & $\begin{array}{l}\text { Early recurrence } \\
\text { and rejection }\end{array}$ & $254 ; 62$ & 5 & $\begin{array}{c}\text { Yes } \\
\text { (3 months) }\end{array}$ \\
\hline 13 & Female & 14 & $\begin{array}{c}\text { Neonatal } \\
\text { hypovolemia }\end{array}$ & 12 & 45 & 48 & 47 & $29 ; 75 ; 112$ & Early rejection & $172 ; 28$ & 34 & $\begin{array}{c}\text { Yes } \\
\text { (2 weeks) }\end{array}$ \\
\hline
\end{tabular}

25(OH)D, 25-hydroxyvitamin D; DDD, dense deposit disease; FSGS, focal segmental glomerulosclerosis; GFR, glomerular filtration rate $\left(\mathrm{mL} / \mathrm{min} / 1.73 \mathrm{~m}^{2}\right) ; \mathrm{GH}$, growth hormone; ND, not done; PTH, parathyroid hormone; PUV, posterior urethral valves; Tx, transplantation 
TABLE 2 Bone mass data for the investigated children

\begin{tabular}{|c|c|c|c|c|c|}
\hline & Study entry & After 1 years & After 3 years & $\begin{array}{c}\text { Delta, } \\
0 \text { to } 1 \text { year }\end{array}$ & $\begin{array}{c}\text { Delta, } \\
0 \text { to } 3 \text { years }\end{array}$ \\
\hline \multicolumn{6}{|l|}{ DXA } \\
\hline \multirow{2}{*}{ TBBMD $\left(\mathrm{g} / \mathrm{cm}^{2}\right)$} & $0.93 \pm 0.12$ & $0.93 \pm 0.13$ & $0.93 \pm 0.18$ & $0.00 \pm 0.04$ & $0.00 \pm 0.13$ \\
\hline & 0.92 (0.77 to 1.19$)$ & 0.92 (0.75 to 1.23$)$ & $0.89(0.70$ to 1.20$)$ & $-0.01(-0.07$ to 0.06$)$ & $-0.01(-0.17$ to 0.19$)$ \\
\hline \multirow{2}{*}{ TBBMD, Z-score } & $0.38 \pm 1.02$ & $-0.39 \pm 0.83$ & $-0.32 \pm 0.86$ & $-0.70 \pm 0.62$ & $-0.70 \pm 0.86$ \\
\hline & $0.40(-1.20$ to 1.90$)$ & $-0.60(-1.40$ to 1.30$)$ & $-0.60(-1.40$ to 1.60$)$ & $-0.50(-2.00$ to 0.10$) * *$ & $-0.80(-2.30$ to 0.50$) *$ \\
\hline \multirow{2}{*}{ TBBMC $(\mathrm{g})$} & $1214 \pm 544$ & $1424 \pm 640$ & $1713 \pm 661$ & $193 \pm 122$ & $499 \pm 272$ \\
\hline & 1034 (464 to 2511$)$ & $1222(568$ to 2717$)$ & 1401 (550 to 2693 ) & 171 (41 to 396 ) $* * *$ & $467(86 \text { to } 1021)^{* * *}$ \\
\hline \multicolumn{6}{|l|}{ DXL } \\
\hline \multirow{2}{*}{ Calcaneal BMD $\left(\mathrm{g} / \mathrm{cm}^{2}\right)$} & $0.36 \pm 0.09$ & $0.36 \pm 0.10$ & $0.39 \pm 0.11$ & $0.01 \pm 0.07$ & $0.04 \pm 0.09$ \\
\hline & $0.38(0.16$ to 0.50$)$ & 0.38 (0.16 to 0.47$)$ & 0.38 (0.21 to 0.55$)$ & $-0.01(-0.05$ to 0.15$)$ & $0.02(-0.07$ to 0.20$)$ \\
\hline \multirow{2}{*}{ Calcaneal BMC (g) } & $0.27 \pm 0.07$ & $0.26 \pm 0.08$ & $0.29 \pm 0.08$ & $0.01 \pm 0.05$ & $0.03 \pm 0.06$ \\
\hline & $0.28(0.12$ to 0.38$)$ & 0.27 (0.12 to 0.36$)$ & $0.28(0.16$ to 0.41$)$ & $-0.01(-0.05$ to 0.11$)$ & $0.01(-0.05$ to 0.15$)$ \\
\hline
\end{tabular}

$B M D$, bone mineral density; $T B B M D$, total body BMD; $B M C$, bone mineral content; $T B B M C$, total body bone mineral content; $D X A$, dual-energy X-ray absorptiometry; $D X L$, dual-energy X-ray absorptiometry and laser. For all measurements, $\mathrm{n}=13$. Values are given as mean $\pm \mathrm{SD}$, median, with minimum and maximum values in parentheses.

$* \mathrm{p}<0.05, * * \mathrm{p}<0.01, * * * \mathrm{p}<0.001$, Wilcoxon signed rank test. 


\section{FIGURES}
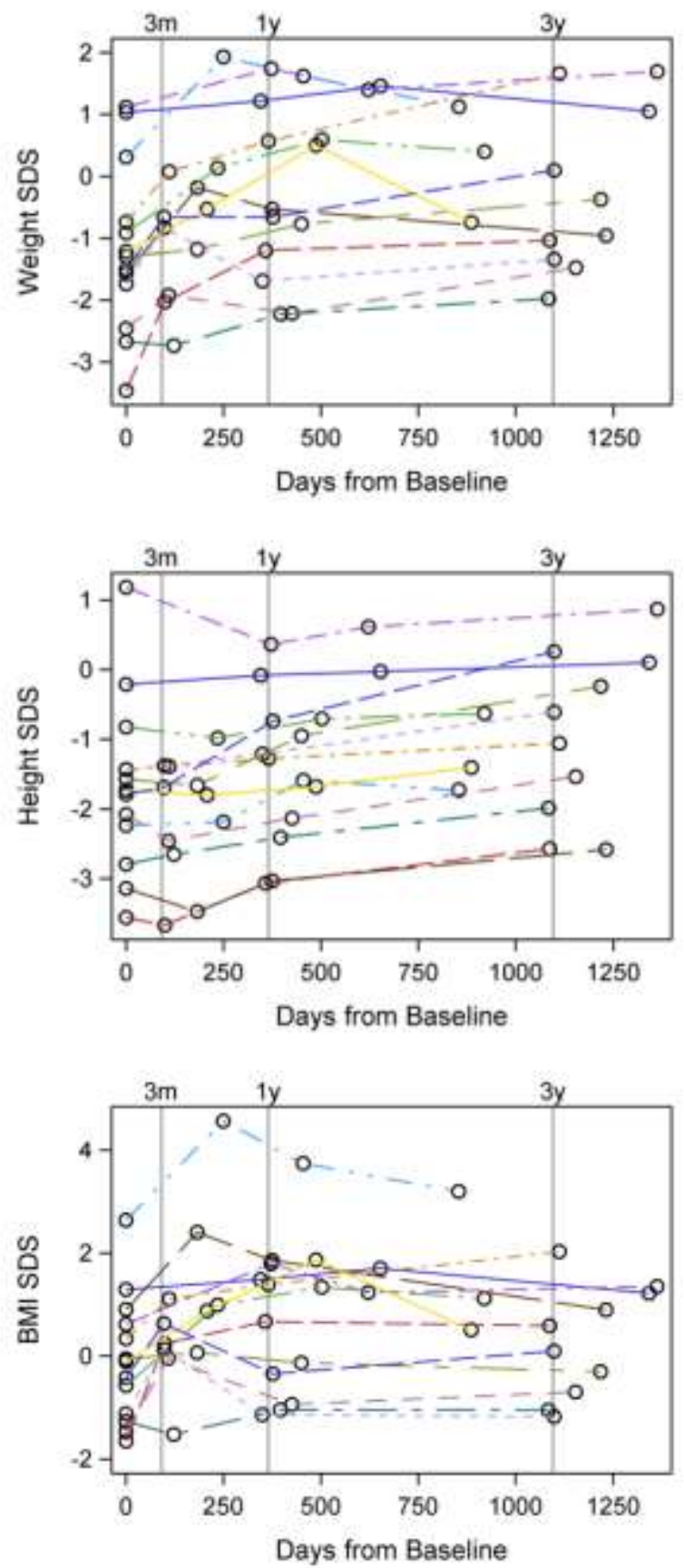

FIGURE 1 Auxological data for weight, height and BMI SDS for each patient over 3 years. 

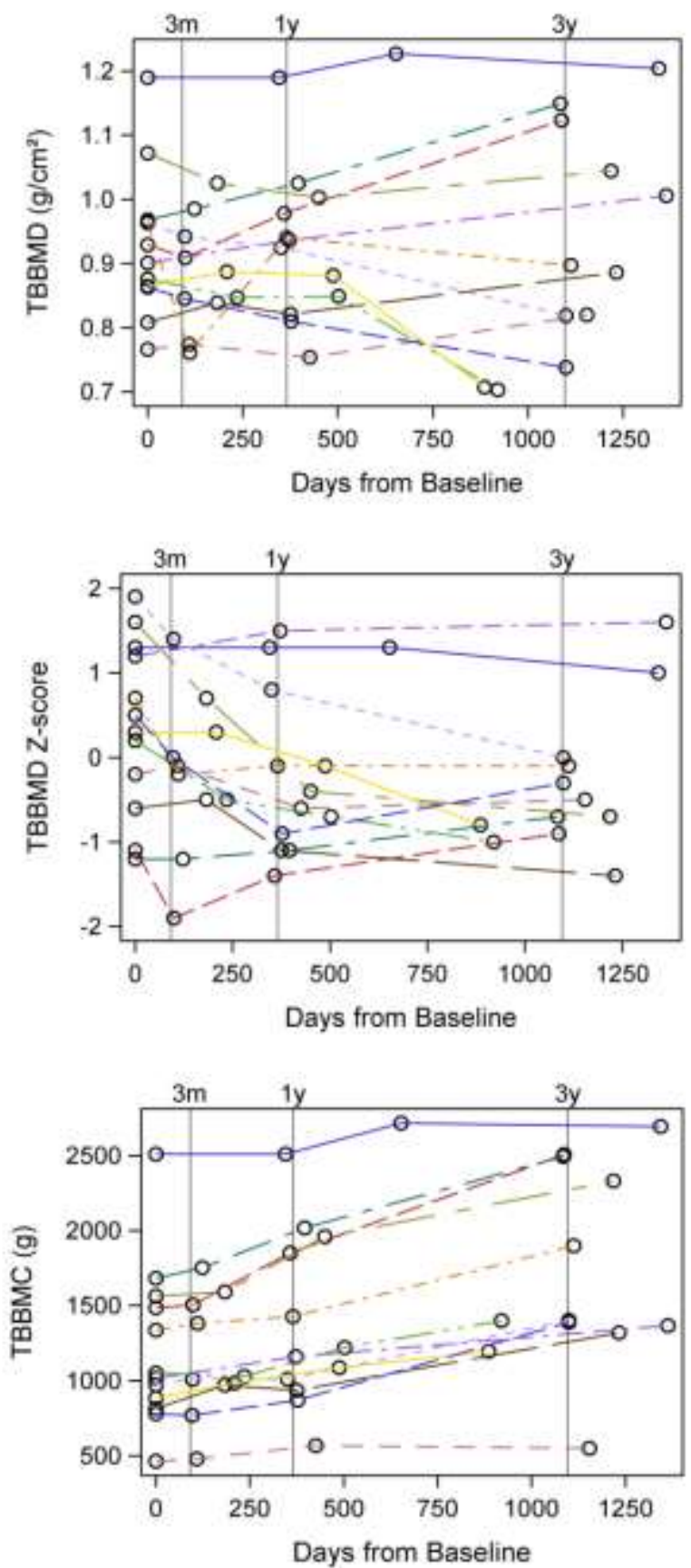

FIGURE 2 Total body bone mass data for each patient over 3 years. 

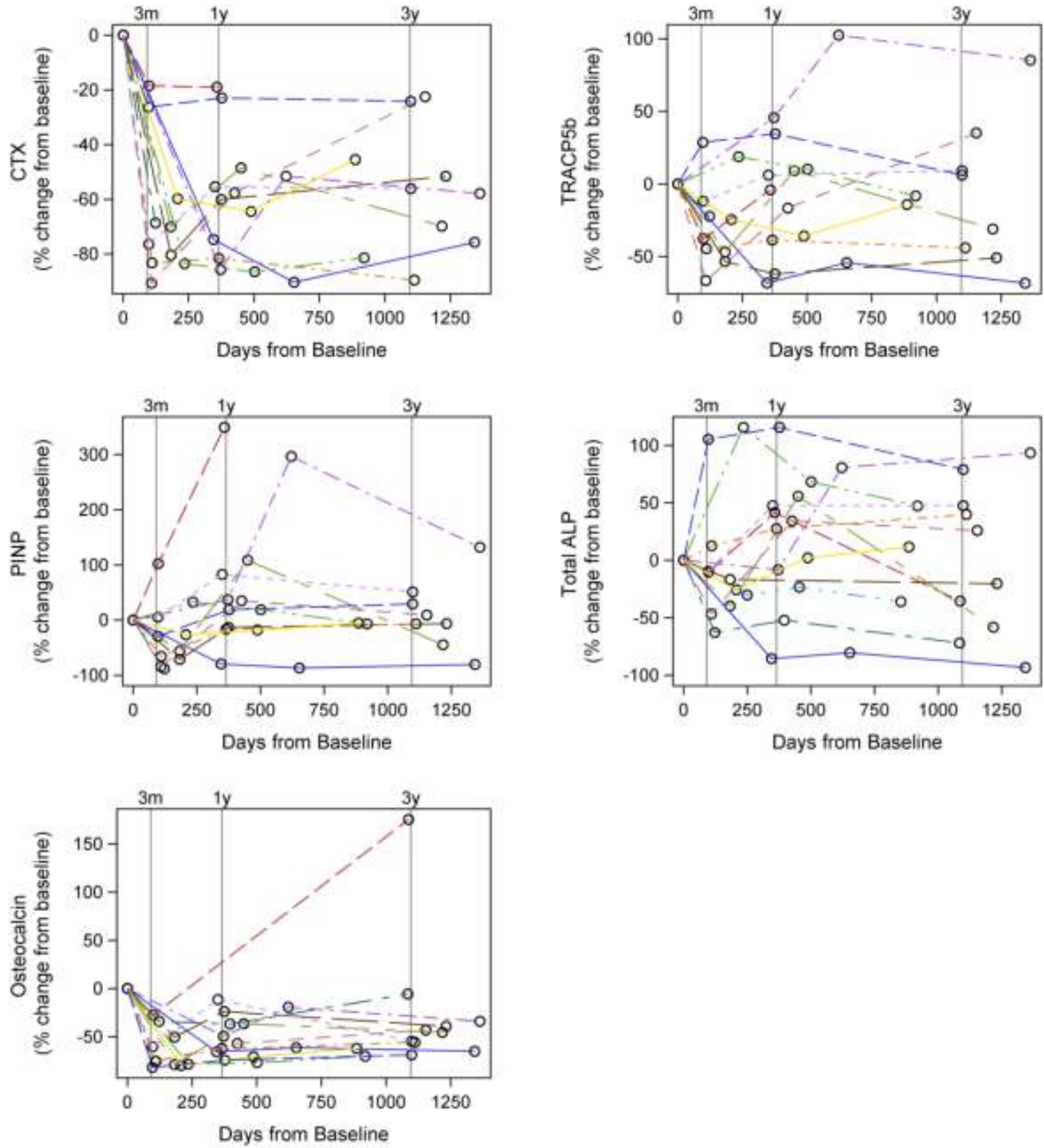

FIGURE 3 Individual data, given as percentage change after kidney transplantation, over 3 years for biochemical markers of bone turnover. 